\title{
O Index para a Inclusão como Instrumento de Pesquisa: uma Análise Crítica $^{1}$ \\ INDEX FOR INCLUSION AS A RESEARCHTOOL: A CRITICAL ANALYSIS
}

\author{
Mônica Pereira dos SANTOS² \\ Alline Gonçalves do NASCIMENTO ${ }^{3}$ \\ Evanir da Rocha MOTTA ${ }^{4}$ \\ Lillian Auguste Bruns CARNEIRO5
}

\begin{abstract}
RESUMO: quando nos propomos a realizar uma pesquisa acadêmica em qualquer área do conhecimento, a coerência com o embasamento teórico em que essa pesquisa está fundamentada constitui um dos principais fatores que respondem pela credibilidade dos resultados que pretendemos alcançar. O distanciamento desse embasamento teórico por qualquer motivo, bem como a tentativa forçada de lhe atribuir novos significados para atender aos objetivos do pesquisador, acaba por descaracterizar a pesquisa, ocasionando uma cisão entre a teoria e o que se pretende atingir na prática. É nessa perspectiva que este artigo apresenta uma análise crítica a um trabalho publicado na coletânea Preconceito e Educação Inclusiva, coordenada por José Leon Crochik e organizada pelo Laboratório de Estudos sobre o Preconceito da USP. O referido trabalho, intitulado Análise de formulário de avaliação de inclusão escolar, traz em si uma contradiçấo entre a teoria em que está fundamentado e o que seus autores realmente pretendem alcançar com a pesquisa, fato que nos chamou a atenção, tendo em vista ser do nosso conhecimento o sentido original da proposta lançada pelo Index para Inclusão, de Booth e Ainscow, trabalho em que os autores se basearam para a realização dessa pesquisa. Nossa intenção é, portanto, assinalar os principais pontos do artigo em questão, que divergem da proposta original do Index para Inclusão, com o objetivo de contribuir para uma melhor compreensão do Index, importante trabalho destinado aos profissionais que se dedicam aos estudos e projetos voltados para a inclusão em educação.
\end{abstract}

PALAVRAS-CHAVE: Educaçáo Especial. Inclusão em Educação. Index para a inclusão. Pesquisa.

\begin{abstract}
When we under take to conduct academic research in any field of knowledge, consistency with the theoretical framework on which such research is grounded is one of the main factors that account for the credibility of the results we intend to achieve. The detachment from this theoretical foundation for any reason, as well as the forced attempt to assign new meanings to meet the researcher's objectives, ends up by mischaracterizing the research, causing a division between theory and the intended achievement in practice. It is in this perspective that this paper presents a critical analysis to a study published in the collection Prejudice and Inclusive Education, coordinated by José Leon Crochick and organized by the Laboratory for Research on Prejudice at USP. Said work, entitled Analysis of an evaluation form for school inclusion, bears a contradiction between the theory on which it is based and what its authors really intended to achieve with the research, a fact that caught our attention, since it is a work based on the Index for Inclusion Booth and Ainscow, and since the meaning intended by Booth and Ainscow for the use of the Index is quite different from the one presented in Crochick's paper. Our intention is, therefore, to point out the main topics of the paper in question, which diverge from the original proposal of the Index for Inclusion, with the objective of contributing to a better understanding of the Index, an important work for practitioners dedicated to studies and projects concerned with inclusion in education.
\end{abstract}

KEYWORDS: Special Education. Inclusion in Education. Index for Inclusion. Research.

\footnotetext{
${ }^{1}$ Nosso especial agradecimento ao nosso colega e amigo de pesquisas, Prof. Tony Booth, que generosamente leu e aprovou as consideraçôes aqui presentes.

${ }^{2}$ Doutora em Psicologia e Educação Especial pelo Institute of Education, da Universidade de Londres, professora da Faculdade de Educação da Universidade Federal do Rio de Janeiro e fundadora do Laboratório de Pesquisa, Estudos e Apoio à Participação e à Diversidade em Educação (LAPEADE), Rio de Janeiro, RJ, Brasil. monicapes@gmail.com

${ }^{3}$ Graduaçáo e Licenciatura em Letras (Português/Libras), da Universidade Federal do Rio de Janeiro e pesquisador do Laboratório de Pesquisa, Estudos e Apoio à Participação e à Diversidade em Educação (LAPEADE). Rio de Janeiro, RJ, Brasil. allinenascimento84@gmail.com

${ }^{4}$ Graduação e Licenciatura em Letras (Latim), da Universidade Federal do Rio de Janeiro e pesquisador do Laboratório de Pesquisa, Estudos e Apoio à Participação e à Diversidade em Educação (LAPEADE). Rio de Janeiro, RJ, Brasil. evanirmotta@yahoo.com.br

${ }^{5}$ Doutoranda da Faculdade de Educação da Universidade Federal do Rio de Janeiro e pesquisadora do Laboratório de Pesquisa, Estudos e Apoio à Participação e à Diversidade em Educação (LAPEADE). Rio de Janeiro, RJ, Brasil. lillian.fundacao@gmail.com
} 


\section{INTRODUÇÃo}

O presente artigo tem como objetivo discutir a proposta apresentada no capítulo intitulado Análise de formulário de avaliação de inclusão escolar, publicado na coletânea Preconceito e Educação Inclusiva, coordenada por José Leon Crochik (2011) e organizada pelo Laboratório de Estudos sobre o Preconceito, da Universidade de São Paulo (USP).

No capítulo que é objeto de análise deste artigo, os autores conceituam educação inclusiva com base na proposta do Index para Inclusão Booth e Ainscow (2002), usando-o como instrumento de pesquisa para verificar o grau de inclusão das escolas de forma a comparálas entre si.

Em que pese a qualidade da discussão conduzida em Crochick et al. (2011), preocupa-nos a menção que os autores fazem ao Index como um instrumento de avaliaçáo e checagem dos processos de inclusấo. Isto porque, como vimos acompanhando o trabalho de seus criadores há muitos anos, fazendo parte da equipe internacional de pesquisa e sendo os tradutores e mais antigos disseminadores e desenvolvedores do Index no Brasil, sabemos que a fundamentação que perpassa a concepção e uso do Index não é a de constituir-se em um instrumento de avaliação, mas sim, em um conjunto de indicadores e questóes infindáveis (portanto, em constante possibilidade de alteração e mudança) que bem refletem a questão da inclusão conforme seu principal autor vem defendendo há décadas: um processo interminável, nunca um estado final possível de se chegar, posto que as exclusóes permeiam nosso mundo e dão sentido à própria ideia de inclusão e vice-versa (BOOTH, 2002, 2011).

Assim sendo, este artigo pretende apresentar uma análise crítica sobre o capítulo supramencionado, tendo em vista explicitar o sentido de inclusão na perspectiva de Booth e Ainscow e, dessa forma, chamar a atenção contra o emprego puramente instrumental do Index para Inclusão, como um instrumento de padronização de culturas, políticas e práticas de processos não passíveis de padronização, como são inclusão e exclusấo.

Dessa forma, apresentaremos, neste artigo, os objetivos originais do Index, alertando para o fato de os autores do capítulo em questão estarem associando de forma equivocada esse importante instrumento de apoio aos pesquisadores, gestores e demais profissionais de educação a um simples manual de aplicação de formulários a serem empregados em pesquisa sobre inclusão. Em outras palavras: tudo o que o Index não deve ser.

\section{Desenvolvimento}

\subsection{O ConCeITo De INCLUSÁo No INDEX}

Desde sua primeira versão, o Index para a Inclusão tem sido apresentado como "um recurso para o desenvolvimento de escolas. Um documento abrangente que pode ajudar a todos a encontrarem seus próprios próximos passos em direção ao desenvolvimento de seus ambientes" (BOOTH; AINSCOW, 2002, p.1). Os autores prosseguem afirmando que tais materiais foram concebidos com a finalidade de "[...] avançar com base na riqueza de conhecimentos e experiências que as pessoas têm sobre suas práticas" (idem). Tais materiais "desafiam e apoiam o desenvolvimento de qualquer escola, independentemente do quáo 'inclusiva' ela creia que seja" (p. 1). 
O Index para a Inclusão está, atualmente (2012), em sua terceira edição. A primeira data de 2000, a segunda de 2002 e a terceira lançada em 2011, tendo sido substancialmente revisada por seu principal autor, Tony Booth. Embora a terceira versão tenha alteraçóes conceituais mais significativas, como por exemplo, a inserção da dimensão curricular dentro do contexto das práticas, o conceito de inclusão desenvolve-se, nas três versóes, de forma consistente a partir da ideia de processo, de investigação e de participação. Ainda que correndo o risco de utilizarmos citaçóes demasiadamente longas dos autores originais, pensamos ser válido corrermos o risco e apontarmos alguns trechos das referidas versóes que se referem diretamente ao que aqui argumentamos, o que faremos a seguir.

$\mathrm{Na}$ versão de 2000, ao definir inclusão, o Index dizia que:

[...] o Index para Inclusão enfoca todos os aspectos da vida escolar e se preocupa com a participação de todos os membros das comunidades de uma escola. A inclusão está ligada ao escrutínio de todas as formas através das quais as escolas podem marginalizar ou excluir alunos. Escolas que são aparentemente bem sucedidas em incluir alguns alunos com deficiências específicas podem, ao mesmo tempo, impedir a participação de outros grupos. Além disso, assumimos a perspectiva de que a inclusão de alunos com deficiências, que são, por sua vez, um grupo largo e variado, fica mais completa quando as escolas respondem a todos os aspectos de suas diversidades (BOOTH; AINSCOW, 2000 p.2, tradução livre; grifos nossos).

A inclusão é, por vezes, vista como envolvendo primariamente o movimento de alunos de fora para dentro do fluxo normal das escolas, com a implicação de que eles sejam "incluídos" uma vez que estejam lá dentro. No entanto, em nossa visão, a inclusão é um conjunto de processos intermináveis. [...] Ela requer que as escolas se engajem num exame crítico do que pode ser feito para aumentar a participação e a aprendizagem da diversidade de alunos dentro da escola e de sua localidade (BOOTH; AINSCOW, 2000, p. 2-3, tradução livre ; grifos nossos).

Já na versão de 2002, o conceito de inclusão seguiu a mesma diretriz:

Todos têm suas próprias percepçóes sobre uma ideia complexa como a inclusão. [...]. É um processo infindável de aumento da aprendizagem e da participação de todos os estudantes. É um ideal a ser aspirado pelas escolas, mas que nunca é totalmente alcançado. Mas a inclusão começa tão logo o processo de aumento da participação seja iniciado. Uma escola inclusiva é aquela que está em movimento (BOOTH; AINSCOW, 2002, apud SANTOS, 2006, p. 2, grifos nossos).

[...] A inclusão se inicia com o reconhecimento das diferenças entre estudantes. O desenvolvimento de abordagens inclusivas ao ensino e à aprendizagem respeita e se baseia em tais diferenças. Isto pode envolver mudanças profundas no que acontece em salas de aula, salas de professores, pátios e nas relaçôes com pais e responsáveis. Para incluir qualquer criança ou jovem precisamos estar preocupados com a pessoa por inteiro. Isto pode ser negligenciado quando a inclusão está focalizada em apenas um aspecto de um estudante, tal como um impedimento ou a necessidade de aprender o inglês como uma língua adicional. [...] precisamos evitar pensar estereotipadamente. Às vezes estas crianças podem ter mais em comum, mesmo no tocante a estes aspectos, com crianças da escola para quem o inglês é uma língua materna do que com estudantes para quem não seja (BOOTH; AINSCOW, 2002, apud SANTOS, 2006, p. 3-4). $\mathrm{O}$ trabalho em identificar e reduzir as dificuldades de um estudante pode beneficiar outros estudantes cuja aprendizagem não era inicialmente um foco de preocupação. Esta é uma maneira através da qual as diferenças entre estudantes, interesses, conhecimentos, habilidades, origens, língua materna, sucesso ou impedimento podem funcionar como recursos de apoio à aprendizagem. [...] (BOOTH; AINSCOW, 2002, apud SANTOS, 2006, p. 4).

Inclusão tem a ver com tornar as escolas lugares estimulantes e apoiadores para o Pessoal e para os estudantes. Tem a ver com a construção de comunidades que encorajam e celebram seus sucessos. Mas a 
inclusão também tem a ver com a construção de comunidades em um sentido mais amplo. As escolas podem trabalhar com outras agências e com as comunidades para promover as oportunidades educacionais e as condiçóes sociais dentro de suas localidades (BOOTH; AINSCOW, 2002, apud SANTOS, 2006, p. 4, grifos nossos).

Por fim, na versão de 2011, inclusão é, uma vez mais, compreendida em linhas semelhantes:

No Index, portanto, inclusão é uma abordagem baseada em princípios ao desenvolvimento da educação e da sociedade. Está ligada à participação democrática no âmbito da educação e além dele. Não se trata de um aspecto da educação relacionado a nenhum grupo particular de crianças. Objetiva aportar coerência ao desenvolvimento de atividades que ocorrem sob diversos títulos de modo a estimularem a aprendizagem e a participação de todos: as crianças e suas famílias, professores, gestores e outros membros da comunidade (BOOTH; AINSCOW, 2011, apud SANTOS; ESTEVES, 2012, p. 20, grifos nossos)

Cada um interpreta inclusão a seu modo. Não é possível abarcar numa única frase conceitos tão complexos como este. [...] Aumentar a inclusão envolve reduzir a exclusão. Envolve combater as pressôes exclusionárias que impedem a participação. Aumentar a participação de todos envolve desenvolver sistemas e ambientaçóes educacionais de modo que estes sejam responsivos à diversidade para valorizar igualmente a todos. Não basta que nossos sistemas e ambientaçóes simplesmente respondam à diversidade das crianças, uma vez que isto ainda pode envolver a criação de uma hierarquia de valor dentro das escolas e entre elas. Em tais casos, as escolas respondem à diversidade selecionando as crianças segundo seus talentos, incapacidade, religiáo e riqueza. A divisão de crianças de acordo com o talento em geral é reforçada desde muito cedo pela imputaçáo de rótulos de habilidade. Isto limita seu prognóstico para realizaçóes futuras e afeta suas expectativas. Quando se valoriza a todos igualmente, a escola acolhe todas as crianças das comunidades circunvizinhas. A inclusão está, portanto, ligada ao desenvolvimento de uma escola que seja para todos; para a educação inclusiva da comunidade nas pré-escolas e nas escolas de ensino fundamental e médio (BOOTH; AINSCOW, 2011, apud SANTOS; ESTEVES, 2012, p. 20, grifos nossos).

[...] A inclusão é vista principalmente como a colocação em prática de valores inclusivos. É um compromisso com determinados valores que explicam o desejo de superar a exclusão e promover a participação. Se não estiver vinculada a valores profundamente enraizados, entấo a tentativa de inclusão pode representar a simples adesão a uma moda qualquer ou atendimento a instruçôes de cima para baixo (BOOTH; AINSCOW, 2011, apud SANTOS; ESTEVES, 2012, p. 21, grifos nossos).

Nas três versóes, verificamos a ideia de processo na medida em que os textos aludem ao conceito de desenvolvimento da escola e argumenta que inclusão não constitui um estado final ao qual se chegar, mas sempre um ideal a se buscar. Esta mesma noção de desenvolvimento da escola, por sua vez, deixa implícito nestes trechos (mas bastante explícito em outros trechos das três versões do Index, aqui não citados) a importância de se ver o Index como um processo investigativo por meio e ao longo do qual reflexóes-açóes sobre a realidade escolar são levadas a cabo. Já a ideia de participação fica clara na medida em que as três versóes conclamam o leitor, consistentemente, a compreender a inclusão em sua relação com o conceito de exclusão e como ação perene, infindável, de combate à mesma por meio do desenvolvimento de processos investigativo-ativos que levam a tomadas compartilhadas de decisões e açóes. Este mesmo compartilhamento é o que fundamenta a participação: ninguém faz inclusão sozinha, nem por decreto. 
Estas acepçôes de inclusão do Index, portanto, atribuem-lhe um papel incompatível com um instrumento de pura aplicação, tal como se fosse um questionário, ou uma lista de checagem. O seu uso neste sentido estritamente instrumental perverte o próprio significado e sentido do Index, "matando", na raiz, aquilo mesmo que é a razão de sua proposição, construção e existência bem-sucedida: defender inclusão como um processo infindável em relação com os fenômenos de exclusão.

Outro aspecto fundamental a ser destacado na concepção de inclusão do Index é seu estreito relacionamento com a proposição, adoção e prática de princípios e valores, dentre os quais, cinco são destacados como mais importantes: participação, igualdade, comunidade, respeito pela diversidade, e sustentabilidade (BOOTH; AINSCOW, 2011 apud SANTOS; ESTEVES, 2012). Destes, os autores dão especial destaque ao princípio da participação. Participação é, assim, conceito chave para se compreender e praticar inclusão. Não pode haver inclusão sem participação. Segundo o Index 2012, participação é definida como:

Participação implica aprendizagem, brincadeira ou trabalho em colaboraçáo com outros. Envolve fazer escolhas e decidir o que fazemos. Num plano mais profundo, tem a ver com ser reconhecido e aceito por nós mesmos (BOOTH; AINSCOW, 2012, p. 11).

Mais elucidativo ainda é o conceito de participação trabalhado em maiores detalhes um pouco mais adiante no Index:

A participação não se resume a isso, mas começa com um simples estar presente. A participação envolve dois elementos relacionados com ação ou atividade participativa além da participação em si. A pessoa participa não só quando está envolvida em atividades comuns, mas também quando se sente envolvida e aceita. A participação diz respeito a estar junto e colaborar com os outros. Diz respeito ao engajamento ativo na aprendizagem. Diz respeito ao envolvimento nas decisóes da vida de alguém, inclusive a educação e os vínculos com ideias de democracia e de liberdade. [...] A participaçáo envolve diálogo com os outros à base de igualdade e, portanto, exige que se deixem propositalmente de lado as diferenças de status e de poder. A participação aumenta quando o engajamento reforça um senso de identidade; quando somos aceitos e valorizados por nós mesmos (BOOTH; AINSCOW, 2012 , p. 22-23).

Em um instrumento que seja visto apenas como "aplicável” a dado contexto, como algo que sirva para avaliar este mesmo contexto, não pode haver participação efetivamente democrática. Não cremos que haja democracia efetiva quando alguém avalia alguém ou alguma coisa tendo em vista classificar este alguém ou algo em termos de mais ou menos inclusivo, como nos parece ser a ideia do capítulo do livro de Crochick et al. (2011), especialmente quando diz:

Para dizer se uma escola é mais ou menos inclusiva, é necessária uma avaliação objetiva que envolva, de um lado, fatores imediatamente observáveis: a existência de adaptação do ambiente físico aos cadeirantes, aos que têm deficiência visual; a existência de carteiras escolares para alunos canhotos ou obesos etc. (...). O Index (BOOTH; AINSCOW, 2002) pode ser utilizado como base para instrumentos que pretendam avaliar o quanto uma escola é inclusiva. Como medida, descreve uma situação estática que permite inferências do dinamismo da situação. Um instrumento desse tipo também expressa uma concepçáo de educação inclusiva que permite gradaçóes possibilitando a comparação entre escolas (p. 173). 


\subsection{O Conceito de InClusấo no CAPítulo de Crochick eT AL.}

No capítulo objeto de análise de nosso artigo, Crochick et al. (2011), referem-se ao Index, já no título, como "Formulário de Avaliação". Apesar de iniciarem-no apresentando uma correta compreensão de como os seus idealizadores o conceberam, acabam por explicitarem, a nosso ver, uma interpretaçáo equivocada sobre a inversão do foco, do "produto", o aluno, para as "condiçóes de produção", a escola.

De fato, Crochick et al. (2011) reconhecem que a proposta do Index não é apenas a de inverter o foco do "produto", mas sim a de ampliar este foco para outros atores igualmente relevantes no cotidiano escolar:

A proposta de Booth e Ainscow (2002) retoma uma discussão importante sobre as condições objetivas de trabalho, que consiste em inverter a atenção do produto para as condiçóes de produção. Em termos educacionais: não se trata de dar ênfase às dificuldades dos alunos, mas às condiçôes da escola para enfrentá-las; aqui as dificuldades dos alunos não são negadas, mas não são apresentadas como obstáculo (CROCHICK et al., 2011, p. 169).

Entretanto, os autores perguntam "se não seria adequado utilizá-lo também como um instrumento de pesquisa para verificar o quanto as escolas são ou não inclusivas de forma a compará-las entre si." Crochick et al. (2011, p. 173), questionamento que constitui o ponto central de nossa crítica: a forma com que os autores empregam o Index para a realizaçáo de sua pesquisa.

É pertinente salientar que além de ser um processo sem fim, a ideia de inclusão perpassa, também, uma perspectiva subjetiva que impossibilita uma padronizaçáo da questáo da inclusão e sua relação com a exclusão. O Index, assim, não é um instrumento de avaliação e de verificação do quanto uma escola é inclusiva ou excludente, como proposto no trecho a seguir, na parte introdutória de conceituação do Index para inclusấo, apresentada no capítulo que é alvo de nossa análise:

Booth e Ainscow (2002) priorizam a atenção para a escola em contraposição a outras concepçóes que focalizam nos alunos em situação de inclusão as dificuldades a serem superadas. $\mathrm{Na}$ concepção destes, os obstáculos ao aprendizado e à participação de todos os alunos são tidos como desafios da escola. A partir disso, os autores criaram um Index que verifica o quanto uma escola é inclusiva e o quanto ela pode vir a ser mais inclusiva, por decisão de seus próprios integrantes (CROCHICK et al., 2011, p. 169).

Porém, ao contrário do que os autores afirmam, o Index para Inclusão tem por objetivo apoiar o processo de desenvolvimento inclusivo da escola, a partir da autorrevisão e junto com a comunidade escolar. Como podemos notar na citação abaixo, retirada da recém - lançada e traduzida versão do Index (SANTOS; ESTEVES, 2012), de Booth e Ainscow (2011), os autores ratificam e fortalecem a intenção explícita do material na versão anterior que baseia nossa análise:

O Index para a inclusão: desenvolvendo a aprendizagem e a participação nas escolas oferece um processo que apoia a autorrevisão e o desenvolvimento de modo alternativo ao de um processo baseado em inspeção, competição e medo de fracasso (SANTOS; ESTEVES, 2012, p. 19). 
Portanto, a iniciação do processo de minimização/eliminação das barreiras à aprendizagem se dá tanto pela identificação das situaçôes excludentes que dificultam a participação dos alunos quanto dos contextos inclusivos para que estes sejam valorizados e sirvam de recurso e apoio para o desenvolvimento de outras práticas mais inclusivas. Deste modo, podemos afirmar que o foco do Index é a eliminação ou minimização dos contextos de exclusão no cotidiano escolar, tendo como agentes de atuação neste processo todos que de alguma forma influenciam a comunidade escolar, como os pais, professores, funcionários, direção e a própria comunidade em que a escola está inserida.

O conceito de Inclusão proposto por Booth e Ainscow (2002) no Index, como sendo um processo infindável de aumento da aprendizagem e da participação de todos os estudantes, traz em si dois outros conceitos que servem como base para entendermos o motivo pelo qual os autores não trabalham com a noção de "necessidade especial" na perspectiva inclusiva.

O primeiro foi parcialmente discutido na seção anterior e refere-se ao conceito de "barreiras à aprendizagem e à participação", que não se restringe a algumas crianças com necessidades educacionais visíveis, mas amplia o foco para os esforços que precisam ser feitos na e pela instituiçáo educacional como um todo e seus atores para minimizar as barreiras, aprimorar a aprendizagem e aumentar a participação de todo e qualquer estudante.

Outro conceito é o de "recurso", que não se limita às verbas disponibilizadas à escola; abrange, sim, tudo aquilo que serve para minimizar as barreiras à participação e à aprendizagem dos alunos. Por exemplo, os próprios estudantes que mediam seu processo de aprendizagem também podem apoiar os colegas; os pais e responsáveis, igualmente, podem trabalhar de forma colaborativa na escola; os professores e a direção, as comunidades do entorno, enfim; tudo que pode ser aproveitado colaborativamente no processo de aprendizagem de todos os alunos.

No entanto, ao se analisar os objetivos do artigo em questão, é possível perceber que, Crochick et al. (2011) propóem uma forma de utilização do Index, que não cabe na proposta original de seus idealizadores. E é a partir dessa proposta que elaboram um formulário para caracterização de escolas inclusivas, com a finalidade de medir, através de pontos, o grau de inclusão dessas escolas. Para isso, os autores afirmam que:

O Index pode ser utilizado como base para instrumentos que pretendam avaliar o quanto uma escola é inclusiva. [...] um instrumento desse tipo também expressa uma concepção de educação inclusiva que permite gradações possibilitando a comparação entre escolas (CROCHICK et al., 2011, p. 172-173).

Os resultados apresentados pelos autores no trabalho que está sendo analisado revelam uma compreensão de educação inclusiva voltada apenas para pessoas com deficiências, o que confirma o emprego equivocado do Index como instrumento de apoio a um processo de inclusão nas escolas. Segundo Booth e Ainscow (2002), a inclusão está frequentemente associada a estudantes que tenham impedimentos, ou seja, vistos como tendo "necessidades educacionais específicas". No entanto, de acordo com que os autores propóem no Index:

Quando as dificuldades são vistas como se originando das 'necessidades educacionais especiais' das crianças e jovens, pode parecer natural pensar no apoio como se referindo à provisão de pessoas adicionais para trabalhar com alguns indivíduos em particular. [Por isto] O Index adota 
uma noção bem mais ampla de 'apoio', como todas as atividades que aumentam a capacidade de uma escola para responder à diversidade estudantil. Prover apoio a indivíduos é apenas parte da tentativa de aumentar a participaçáo dos estudantes. $\mathrm{O}$ apoio também é proporcionado quando os professores planejam as aulas com todos os estudantes em mente, reconhecendo seus diferentes pontos de partida, experiências e estilos de aprendizagem ou quando os estudantes ajudam-se mutuamente. Quando as atividades de aprendizagem são designadas para apoiar a participação de todos os estudantes, a necessidade de apoio individual é reduzida. Igualmente, a experiência de apoio a um indivíduo pode levar a um aumento na aprendizagem ativa, independente, bem como contribuir para a melhoria no ensino para um grupo mais amplo de estudantes. O apoio é uma parte de todo o ensino e todo o Pessoal está envolvido nele. Uma maior responsabilidade pela coordenação do apoio pode estar a cargo de um número limitado de pessoas, mas ao se planejar como o apoio é coordenado torna-se essencial associar o apoio a indivíduos e grupos ao Pessoal e atividades de desenvolvimento curricular (apud SANTOS, 2006, p. 9-10).

A pesquisa realizada por Crochick et al. (2011) trata de questóes pontuais, referindose a grupos específicos como, por exemplo, alunos com deficiência visual, auditiva ou dificuldade de aprendizagem, considerando mais inclusiva a escola que oferece suporte a esses alunos. Do mesmo modo, a escola que oferece rampas, corrimãos ou elevadores para alunos cadeirantes, recebem, segundo os autores, maior conceituação com relação à inclusão.

É importante esclarecer que em momento algum nos colocamos contra a adaptação do ambiente escolar para receber pessoas com deficiências. Essas questóes, inclusive, já são tratadas legalmente, e os ambientes sociais devem, obrigatoriamente, ser adaptados para receber essas pessoas. Porém, não se pode considerar que uma escola passaria a ser mais inclusiva apenas por oferecer aos alunos cegos o sistema Braile ou aos alunos surdos a Língua Brasileira de Sinais (Libras). Do mesmo modo, a escola não seria mais inclusiva apenas por proporcionar aos cadeirantes mais facilidades de acesso por meio de rampas, corrimãos e elevadores. Embora essas medidas facilitem o acesso de pessoas com deficiências ao espaço escolar e apontem para uma escola mais preocupada com a inclusão, convém lembrar que a inclusão não se garante somente pelo acesso. Inclusão implica, como já dissemos, participação efetiva, com direito e colocação em prática de atitudes de decisão.

Se, no entanto, o Index for utilizado como um instrumento que simplesmente "se aplica” a dado contexto, seu potencial de promover a participação fica perdido. A ideia do Index é a de que ele seja desenvolvido em um processo na escola, e não aplicado como um instrumento de avaliação. Isto é o que lhe dá um caráter emancipatório e político pertinente, portanto, ao ideário da inclusão, posto que desencadeia nas instituiçôes um processo dialógico de autorrevisão com a colaboração (mas nunca com os ditames) dos pesquisadores como coautores neste processo, e nunca como direcionadores do processo.

Esta questão da colaboração é uma das características que, aliás, na visão dos autores, diferencia inclusão da velha proposta de integração. Com base no que conhecemos sobre a proposta dos idealizadores do Index para a Inclusão, podemos afirmar que, ao contrário da integração, que é um processo através do qual os indivíduos são apoiados para que lhes seja permitida a participação nos programas das escolas, a inclusão aponta, pelo contrário, para a reestruturação das escolas em sentido de compartilhamento de poderes e decisóes, de forma a responder à diversidade dos indivíduos que a frequentam. A inclusão em educação, portanto, 
constitui-se em um processo através do qual a escola tenta responder a todos os alunos enquanto indivíduos, reconhecendo, reestruturando a sua organização curricular e a provisão de utilização de recursos para reconhecer a todos e cada um de seus atores como sujeitos com igual valor como seres humanos e com iguais direitos. Através deste processo, a escola constrói a sua capacidade de acolher a todos os alunos provenientes da comunidade local que a desejem frequentar, promovendo, assim, a inclusão desses alunos no ambiente escolar.

\subsection{REINTERPRETANDO AS PRÁTICAS EDUCATIVAS À LUZ DO INDEX}

Entendendo o importante papel que a universidade tem na sociedade, ainda mais quando lhe é solicitado participar na solução de problemas referentes à minimização de barreiras à aprendizagem e à participação, o grupo de pesquisa vem desenvolvendo o Index em espaços educacionais onde são observadas situações de inclusão/exclusão. Sempre procurando estender o convite ao diálogo e à participação a todos aqueles envolvidos, mesmo que direta ou indiretamente, a prática do grupo de pesquisa busca ser, verdadeiramente, uma ação participativa.

A inclusão, entendida sob a ótica omnilética, tem auxiliado os grupos a definir, coletivamente, suas prioridades estratégicas, além de converter as discussóes sobre os desafios enfrentados em culturas, políticas e práticas de combate às exclusóes presentes no universo observado e, nela, o trabalho com as dimensões do Index.

Segundo Santos (2008), ao eleger os pontos positivos e desafios da atividade humana, os fenômenos - culturais, políticos e práticos - podem ser identificados e estes estão obrigatoriamente presentes para quem pensa a prática inclusiva em espaços socializados. Como uma percepção gestáltica, esta tridimensionalidade dialética e atemporal propõe uma compreensáo daquilo que está além do visível, do evidente. Importante notar que essa percepção não admite o estabelecimento de uma base fixa e que a complexidade do pensamento humano pode buscar como referência primeira, tanto a prática como a cultura ou a política. Essa triangulação dependerá, exclusivamente, do ponto de partida definido por quem se debruça sobre a questão da inclusão.

Partindo desse entendimento, a leitura do Index torna-se um momento de reflexão sobre as possibilidades de transformação das práticas diárias, seja na escola ou em outro ambiente social, como um referencial teórico. Basta uma rodada de leituras do Index, uma discussão sobre os conceitos que definem as noçóes de barreiras à aprendizagem e à participação para que observemos a gama de oportunidades de interpretaçóes que esse material oferece e que tocam de maneira quase íntima cada um que o estuda.

De acordo com Booth e Ainscow (2002):

A noçáo de barreiras à aprendizagem e à participaçáo pode ser usada para direcionar a atenção àquilo que precisa ser feito para aprimorar a educação para qualquer criança. Os estudantes encontram dificuldades quando eles experimentam barreiras à aprendizagem e à participação. Barreiras podem ser encontradas em todos os aspectos da escola, bem como nas comunidades e em políticas locais e nacionais. Barreiras também surgem na interação entre estudantes, na maneira como são ensinados e o que são ensinados. Barreiras à aprendizagem e à participação podem prejudicar o acesso à escola ou limitar a participaçáo do sujeito dentro da escola (BOOTH; AINSCOW, 2002, p. 40). 
O trabalho de leitura e estudo do Index com grupos deve, preferencialmente, iniciar com a leitura do material e de seus indicadores. Em seguida, a sugestão é propor a escolha de indicadores que mais se aproximam com as questóes prementes no dia a dia do grupo, identificando pontos positivos e negativos da sua prática diária. Estes pontos, positivos e negativos, eleitos pelo grupo, devem ser revistados, agora à luz dos indicadores do Index, suscitando, assim, discussões que instigam a identificação das culturas, políticas e práticas existentes no subtexto da ação social de cada um. Desses encontros, tensóes surgem, pois ao confrontar sua prática diária com as proposiçóes do Index, as discussóes devem avançaram para o entendimento da complexidade daquilo que terão que encarar mais adiante.

\section{Conclusấo}

Apresentamos, através desse artigo, uma breve análise crítica sobre o emprego inadequado do Index para Inclusão como um instrumento fechado de avaliação. Tal procedimento se deu no trabalho realizado por Crochick et al. intitulado Análise de formulário de avaliação de inclusão escolar, que integra a coletânea Preconceito e Educação Inclusiva, coordenada por José Leon Crochik (2011) e organizada pelo Laboratório de Estudos sobre o Preconceito da USP.

Embora o referido trabalho apresente o importante resultado de uma pesquisa voltada para a inclusão escolar, aqui nos propusemos a analisar a forma como seus autores utilizaram o Index, referindo-se a esse relevante material (destinado a apoiar a promoção da inclusão em educação numa perspectiva de emancipação) como se fosse um manual de orientaçóes para a elaboração de questionários de pesquisa. Além disso, os autores do capítulo também não deixaram claro de que forma os indicadores do Index foram empregados, que critérios usaram para selecionar o que pareceu ser alguns dos indicadores e náo outros, posto que no referido capítulo o que aparece como aspectos constituintes do "formulário" que propóem em quase nada se assemelham ao Index. Na seção intitulada "Método", do capítulo de seu livro, os autores apenas dizem:

O instrumento Formulário para caracterização de escolas inclusivas (ver anexo 1) foi elaborado a partir do Index produzido por Booth e Ainscow (2002), com o objetivo de caracterizar escolas segundo seu grau de inclusão e é composto por oito questóes, seis com alternativas de respostas e duas abertas (CROCHICK et al., 2011, p. 174).

Conhecedores que somos do importante trabalho realizado por Booth e Ainscow (2000, 2002, 2011), não poderíamos nos calar diante da constatação de que os conceitos e propostas defendidos por esses pesquisadores estão sendo interpretados e aplicados de maneira contraditória ao que defendem como um caminho a ser seguido em pesquisas e projetos voltados para a inclusão em educação.

Dessa forma, cumpre-nos esclarecer que, em que pese toda nossa admiração e respeito pelos autores dos capítulos do livro aqui discutido, precisamos apontar que, longe de ser um simples manual ou formulário que se destina a avaliar se uma instituição escolar é inclusiva ou não, o Index para Inclusão é um indispensável referencial para aqueles pesquisadores, professores e demais profissionais de educação que se dispóem a trabalhar para a promoção da inclusão em educação nas instituiçôes educacionais. 
Por fim, com esta discussão, esperamos esclarecer as intenções e conceitos propostos por Booth e Ainscow, de forma a contribuir ainda mais para a difusão do apoio a redução e/ ou extinção das barreiras à aprendizagem e à participação, que impedem o processo inclusivo no cotidiano escolar.

\section{REFERÊNCIAS}

BOOTH,T.; AINSCOW, M. Index for inclusion - developing learning and participation in schools. Bristol: CSIE, 2000.

_. Index for inclusion - developing learning and participation in schools. Bristol: CSIE, 2002. . Index for inclusion - developing learning and participation in schools. Bristol: CSIE, 2012.

CROCHICK, L. et al. Preconceito e educação inclusiva. Brasília, DF: SDH/Presidência da República, 2011.

SANTOS, M.P. Index para inclusão. Desenvolvendo a aprendizagem e a participação na escola. Produzido pelo LaPEADE, 2006.

SANTOS, M.P.; PAULINO, M.M. Inclusão em educação: culturas, políticas e práticas. 2.ed.São Paulo: Cortez, 2008.

SANTOS, M.P.; ESTEVES, J.B. Index para inclusão. Desenvolvendo a aprendizagem e a participação na escola. Produzido pelo LaPEADE, 2012. Disponível em: <http:/www.lapeade.com.br/publicacoes/ documentos/index2012final\%20FOTOS\%20BRASIL.pdf >. Acesso em: 19 dez. 2014. 
SANTOS, M. P. et al. 